\title{
Intención de voto y la evaluación de los candidatos: los jóvenes mexicanos en 2018
}

\author{
http://dx.doi.org/10.15304/rips.18.1.5755 \\ Héctor Gutiérrez Sánchez \\ UNIVERSIDAD AUTÓNOMA QUERÉTARO \\ ciudadanohector@yahoo.com.mx
}

Resumen: Por muchos años, la teoría de la modernización prevaleció como la principal explicación del abstencionismo mexicano. Sin embargo, este enfoque ha sufrido importantes reveses teóricos y empíricos, lo que propició la búsqueda de nuevas explicaciones. Entre las nuevas propuestas, se encuentra la posibilidad de que los mexicanos voten menos porque no encuentran candidatos aceptables de acuerdo con una evaluación pragmática (es decir, por su experiencia profesional/laboral) o moral, pero no hay prueba empírica de ello y la evidencia internacional tampoco es concluyente al respecto. Se aprovechó la elección 2018 para levantar una encuesta para poner a prueba esta hipótesis, encontrándose que incluso si se controlan un par de factores («apego partidista» y «creencia en que se debe votar aun si los candidatos son malos»), la mala evaluación de los candidatos sí se relaciona con el abstencionismo. Además, se encontró que la dimensión moral de este juicio hacia los candidatos se relaciona más con la tendencia a votar que otros aspectos como la formación académica y profesional del candidato o sus propuestas y equipo de trabajo. Finalmente, esta tendencia parece fluctuar entre ciudades, habiendo regiones donde el peso de lo moral prevalece, mientras que en otras lo profesional y académico determina más el abstencionismo.

Palabras clave: abstencionismo, desencanto político, jóvenes, participación política.

Abstract: For years, the theory of modernization was the main explanation of voter turnout in México, but this theory has had important theoretical and empirical reverses, which led researchers to look for new explanations, among them is the possibility that citizens vote less because they do not find acceptable candidates in either a pragmatic (professional/work experience) or moral evaluation, but there is no empirical evidence of this and the international evidence is not conclusive either. Little before the Mexican 2018 election, a survey was made to test this hypothesis, finding that even controlling a couple of factors (partisan attachment and belief that one should vote even if all candidates are bad), the poor evaluation of candidates is relates to abstentionism. It was also found that the moral component of the evaluation has a stronger relationship than other aspects such as the academic and professional career of the candidate. Finally, the relationship found seems to fluctuate between cities, there seems to be regions where the weight of the moral prevails, while in others the professional and academic aspect determines more of the voter turnout.

Keywords: voter turnout, political disenchantment, youth, political participation. 


\section{Introducción}

a participación electoral (aquí analizada proyectivamente como «intención de voto») es un elemento indispensable para la consolidación de cualquier democracia. Aunque unas elecciones concurridas no son sinónimo de democracia, ésta depende de las votaciones, porque son su principal fuente de legitimidad. La participación electoral es especialmente relevante para democracias jóvenes como la mexicana que aún luchan por consolidarse, pues una baja participación política podría desanimar las fuerzas sociales que intentan consolidar dicho sistema de gobierno (Zovatto, 2006). Quizá en democracias ya consolidadas se pueden tener bajas en la participación sin que eso represente un riesgo, pero el caso mexicano necesita elecciones concurridas.

Además, el presente estudio se concentra en el caso de jóvenes, población donde estos asuntos son particularmente relevantes. Primero, se trata de personas que apenas están ingresando al sistema político formal, por lo que seguirán en él por varias décadas (de ahí que sus rasgos y actitudes serán relevantes por muchos años). Por otro lado, los jóvenes mexicanos parecen tener una actitud muy negativa sobre lo político y particularmente sobre el funcionamiento de la democracia (Ponte, 1998). Esta población se caracteriza por una fuerte desconfianza institucional. No parece que los jóvenes estén del todo desentendidos o desinteresados de lo político, pero sí parecen poco vinculados con las instituciones formales (Urbina, 2014). Este alejamiento con las instituciones es un problema para éstas últimas.

Así, la intención de voto es un asunto relevante para el bienestar de la democracia mexicana, particularmente al indagarse en población joven. La literatura sobre el asunto nos deja claro que los jóvenes se están distanciado de las instituciones políticas formales, pero en realidad sabemos poco sobre por qué votan o no los jóvenes mexicanos. El presente texto revisa la hipótesis de si una mala evaluación hacia los candidatos se relaciona con una baja intención de voto.

Este trabajo comienza discutiendo sobre jóvenes y política, mostrando cuán bajo es su involucramiento en las instituciones democráticas. De ahí se pasa al análisis sobre la participación electoral, comenzando con las teorías clásicas que desembocan en la teoría de la modernización, primera gran teoría sobre la participación en México. Sin embargo, esta explicación ha sido muy cuestionada, lo que dio lugar a la búsqueda de nuevas variables independientes, como, por ejemplo, que la mala evaluación ciudadana de los políticos podría llevar a menor participación. Luego este argumento nos lleva a discutir con el asunto del apego partidista, mismo que se supone también determina la participación e incluso podría controlar estadísticamente el peso de la evaluación ciudadana. 
Así pues, hay razones para pensar que la evaluación de los candidatos podría determinar la intención de voto, pero al no tener certeza sobre ello, se propone utilizar un método cuantitativo para revisar la relación entre estas variables. En la metodología se describe la obtención de los datos y en los resultados se muestra el tipo de relación que se encontró entre las variables. Al final se encuentra que -efectivamentela evaluación relativa a los candidatos parece relacionada con la intención de voto, particularmente en su dimensión moral.

\section{Jóvenes, participación y evaluación de los políticos}

Como se mencionó antes, este estudio se concentra en población juvenil, más específicamente en estudiantes mexicanos de licenciatura. Esta población es de las más estudiadas en cuanto a su involucramiento en lo político. Desafortunadamente, las investigaciones tienden a describir a un grupo social más bien apático, sobre todo en relación con la parte más institucional de la participación. Es decir, los estudios dibujan una juventud mexicana con interés político, pero distante y desconfiada de las instituciones formales y los políticos.

Por ejemplo, Cuna (2006) habla de cómo hay un divorcio entre los partidos políticos y los jóvenes, quienes sí son blanco de mercadotecnia en periodos electorales, pero que no son realmente tomados en cuenta por los partidos. Por su parte, los jóvenes mexicanos muestran una fuerte desconfianza en la política y una muy baja filiación partidista. Hay una hipótesis optimista (Salazar, 2002) según la cual una baja participación política formal en los jóvenes no debería preocuparnos, pues sería un síntoma de consolidación democrática. Esto bajo el supuesto de que una regularización democrática reduciría las confrontaciones entre posturas y con ello se destensarían los mecanismos electorales competitivos. Sin embargo, esta hipótesis asumiría un grado de consolidación democrática que no parece coincidir con el caso mexicano.

Casi todo estudio político sobre jóvenes mexicanos habla de un distanciamiento entre éstos y las instituciones políticas formales, sin embargo, no todo es pesimista. Por ejemplo, los jóvenes estudiantes de México parecen «demócratas insatisfechos» (Cuna, 2012), es decir, son personas que sí están muy insatisfechas con los resultados del gobierno y con los actores políticos, pero aun así apoyan a la democracia. Esto se logra porque los jóvenes no creen vivir en una «verdadera» democracia, lo que les permite tener una buena imagen de la democracia como un ideal y a la vez estar molestos con su gobierno factual.

Todo esto es una especie de bendición mezclada, pues si bien se rescata el apoyo a la democracia, se mantiene el descontento con las instituciones políticas. Del mismo modo, generalmente se encuentra que los jóvenes sí tienen cierto interés político. 
Pero dicho interés no se encamina hacia las elecciones o los partidos políticos. Entre los jóvenes «La mayoría no participaría en las instituciones políticas tradicionales. Y aunque hay quienes declaran tener ideas políticas, ánimo y ganas de participar, no ven en los partidos una opción para ellos» (Cuna, 2006:122)

Pese a la existencia de buenas noticias y los síntomas de interés político, tampoco es posible ignorar del todo la relevancia de la participación formal. Es bueno que los jóvenes tengan inquietudes y busquen modos alternativos de participar políticamente, pero también es relevante que se hagan oír a través de mecanismos formales como las elecciones. Los jóvenes tienen ciertas particularidades electorales en el tema de la participación. Por ejemplo, se sabe que hay una especie de pico de participación la primera vez que se puede votar, por lo tanto los jóvenes tiendan a votar más la primera vez que pueden hacerlo en comparación con elecciones subsecuentes. Sin embargo, no hay mucha teoría específica sobre por qué este grupo de edad vota o no en el caso mexicano. Debido a esto, a continuación, se revisarán teorías generales sobre por qué la ciudadanía mexicana vota o no lo hace. De vez en cuando será necesario revisar el contexto internacional para tener algunas referencias, pero serán acotaciones breves.

Comprender los estudios sobre comportamiento electoral en México pasa por entender el contexto de donde surgen. A partir de 1980, el partido hegemónico mexicano comenzó a descomponerse, lo que volvió relevante el tema electoral y a su vez hizo que se le comenzara a investigar. En aquellas décadas se pensaba que una población con una cultura política cada vez más democrática estaba chocando con estructuras formales del partido hegemónico. Esto no sólo provocaba una molestia ciudadana, sino también un aumento en la participación política de estos nuevos ciudadanos más democráticos (Alonso, 1994; Krotz, 1990).

Desde aquellos años, se intentó explicar la conducta electoral (abstencionismo incluido) principalmente mediante tres enfoques: racional, psicológico o sociológico. El primero probablemente es el menos popular en México. Según este, votar o abstenerse es resultado de un cálculo individual determinado por la probabilidad de que el voto del sujeto decida la elección, cuán diferentes son los candidatos, el costo de votar y la obligación moral de hacerlo (Riker y Ordeshook, 1968). Salvo algunas excepciones, este enfoque casi no se usa en la ciencia política mexicana.

El modelo psicológico es más común entre los investigadores mexicanos. En términos generales, este enfoque propone que las personas en edades muy tempranas aprenden valores e ideologías que ulteriormente determinarán su comportamiento político. En esta corriente se encuentra el concepto de «cultura política» ya mencionado en párrafos anteriores, pero también incluye el modelo Michigan o -más precisamente- el asunto del apego partidista, que será importante más adelante en el texto. 
Finalmente, el enfoque sociológico se basa en los trabajos de Lazarsfeld «The people's choice» (1969) y «Mass Communication, Popular Taste, and Organized Social Action» (1948). La premisa aquí es que la conducta electoral está determinada por el grupo social al que se pertenece. Bajo esta idea, se podría pensar que la clase baja votaría de una forma distinta a la alta, los de mayor educación diferente a los de baja, etcétera. Esta premisa es difícil de eludir, pues resulta complicado no considerar variables tan básicas como educación, ingreso o condición urbano/rural. Estas variables fundamentales están presentes en prácticamente cualquier estudio de ciencias sociales.

El enfoque psicológico y el sociológico se han usado mucho para explicar el abstencionismo mexicano, pero en una especie de mezcla de ellos: La teoría de la modernización. Por varias décadas, esta teoría fue la principal explicación del abstencionismo mexicano. Según ella, el proceso de modernización nacional se llevaría a cabo en bloque. De este modo, conforme México deja de ser agrario y se vuelve citadino, ocurren cambios en las mecánicas familiares, aumenta el ingreso, la educación entre otros cambios propios de la «modernización» o del «desarrollo», incluyendo la modificación de la conducta política. Esto no sólo debería implicar una creciente inconformidad con las estructuras autoritarias de un partido hegemónico, también debería incluir cierto aumento en la sofisticación política e implicar una mayor participación electoral.

Reyna (1971) escribió uno de los primeros trabajos con este esquema, y la idea se arraigó, al grado que trabajos de punta con estadística espacial siguen usando variables como el ingreso o la educación para explicar el abstencionismo mexicano (Lizama, 2012). Sobre la hegemonía de este enfoque, Vilalta (2004) agrega que la teoría de la modernización no sólo está presente en muchos trabajos sobre abstencionismo, sino que en muchos de ellos ya ni siquiera se le explicita o menciona, dándola por obvia.

Pese al éxito del que gozó la teoría de la modernización, se han hecho críticas importantes a esa idea. Molinar y Vergara (1998) señalan que cuando se pone a prueba esta idea, se suele trabajar con unidades agregadas, por lo que se corre el riesgo de una falacia ecológica. Otros investigadores señalan que: «Los resultados obtenidos confirman que en el caso de México [...] la participación electoral no aumenta como consecuencia del desarrollo, más bien nos enfrentamos al fenómeno opuesto» (Lehr, 1985: 61). De acuerdo con Holzner (2007), la teoría de la modernización a veces coincide con los datos empíricos y a veces no, dependiendo del año y lugar de la elección. Sí parece haber una relación entre desarrollo y participación, pero cambia en el tiempo y presenta irregularidades. Algunas ciudades turísticas gozan de un alto nivel de desarrollo, pero presentan participaciones bajas (Sonnleitner, 2007), por lo que 
«los análisis realizados en México sobre este tema no generan evidencia suficiente para probar ni desaprobar esa hipótesis» (Morales, et al., 2011: 25).

Dada esta ambigüedad, conviene revisar un poco esta teoría a nivel internacional. Se sabe que los países más desarrollados sí tienen mayor participación electoral, pero también en otras naciones hay complicaciones. En Honduras, la relación entre indicadores de desarrollo y participación fluctúa, siendo mayor a inicios de los 80 s y casi desapareciendo en los 90s. Además, cambia según qué indicador se utilice, el abstencionismo tiene -por ejemplo- una relación con la desnutrición y otra con el ingreso (Cálix y Sonnleitner, 2006). Lehoucq y Wall (2001) mostraron cómo en las votaciones legislativas y presidenciales de Guatemala no hay relación entre los indicadores de desarrollo y la participación, pero sólo en primeras vueltas, pues en segundas sí aparece esta relación. Nuevamente, la evidencia no sugiere directamente que la teoría de la modernización es falsa, pero sí deja claro que el enfoque es insuficiente.

Esta insuficiencia teórica ha llevado a ciertos investigadores a buscar otras variables que podrían explicar la participación. Entre ellas está el asunto de la mala imagen de los políticos o -más en general- el desencanto político. Esta variable es muy relevante al trabajarse con jóvenes, pues -como se dijo antes- se sabe que esta población está muy poco satisfecha con las instituciones y actores políticos, por lo que no tiene mucho interés en participar en la política formal.

Puesto así, la idea es clara: una ciudadanía insatisfecha con su gobierno y gobernantes se aleja de todo ello y deja de votar. Sólo 3 años después del cambio de partido en la presidencia se relacionó esta insatisfacción ciudadana con una baja en la participación electoral (Morales y Rodríguez, 2003) y la tendencia se arraigó. Dicha molestia se ha relacionado con la abstención y otras formas de no-participación como el voto nulo (Lutz, 2005 y 2005a). Se suele pensar que cuando la ciudadanía no es convencida por ningún candidato, no vota (Alonso, 2010), aunque también se han propuesto otros mecanismos como un individualismo extremo posmoderno donde las personas ya no se interesan en lo público (López, 2013).

Pese a lo anterior, la relación insatisfacción política-participación no es obvia, recordemos que, en el México de los 80s, parecía que los más democráticos eran los más inconformes y también los que más votaban. Además, la evidencia empírica es más bien escasa, ya que casi todos los trabajos que vinculan estos elementos lo hacen con ensayos más que con correlaciones u otras formas de evidencia empírica.

Sólo un trabajo (Gutiérrez, 2017) presenta algo de evidencia empírica al respecto, aunque incluso ese estudio encuentra cierta postura la cual indica que se debe votar aun si los candidatos no convencen, lo que hace aun más dudosa la relación. Dicho texto -además- sugiere que la molestia ciudadana se enfoca mucho más en personas 
particulares que en instituciones, lo que nos lleva a discutir la otra gran teoría del abstencionismo: El apego partidista. Según éste, son los partidos (instituciones, más que personas), lo que determinan tanto la intención de voto como el juicio ciudadano.

Como se dijo antes, el modelo Michigan es parte del enfoque psicológico y sugiere que elementos tempranos en la socialización de las personas determinan su actuar político. Si bien el modelo Michigan se suele utilizar para explicar por quién votan las personas, también es útil para entender si lo hacen o no. Se ha encontrado que los mexicanos que sí se identifican con algún partido tienden a votar significativamente más (Moreno y Méndez, 2007). También se ha sugerido que la variable del partidismo controla estadísticamente a otras, incluyendo la opinión que las personas tienen del presidente saliente o de los candidatos. Moreno (2009) sugiere que el apego partidista determina la participación y también la evaluación de los candidatos.

Esto es un argumento relevante, porque antes se ha hablado de cómo la mala evaluación ciudadana de los candidatos podría relacionarse con la participación. Pero si el juicio ciudadano está determinado en primer lugar por el partidismo, entonces es este último la causa «real» y el juicio a los políticos sólo podría tener una relación espuria. Por lo tanto, el presente trabajo indaga si la evaluación de los candidatos determina la participación y Moreno (2009) pareciera refutar esa propuesta con evidencia empírica. Esto hace que el partidismo deba ser observado cuidadosamente durante toda la investigación.

Pese a lo anterior, hay importantes críticas al modelo Michigan, como la sustantiva disminución de los apegos partidistas, -particularmente en jóvenes- (Gutiérrez y Ávila, 2018) y la propuesta de «Movilización cognitiva» (Dalton, 1984). Además, la elección mexicana 2018 fue ganada ampliamente por un partido reciente y centrado en un líder carismático venciendo así a los partidos políticos consolidados. Esto último nos regresa a la idea de que quizá las personas no ponen tanta atención a las instituciones (partidos incluidos), sino a las personas en particular. De ser este el caso, la mala evaluación de personas específicas (candidatos) debería estar relacionada con la intención de votar.

Poner atención en las personas (candidatos) y no en los partidos nos hace alejarnos del modelo Michigan e implica acercarnos al tema de los liderazgos. El liderazgo en política es un asunto complicado y de orígenes remotos, desde los trabajos políticos de los griegos clásicos hay ya reflexiones sobre los hombres con grandes destinos. Existen análisis que se concentran en los líderes como idealistas que guían a sus seguidores hacia proyectos distantes o utópicos, igualmente, otros analizan los líderes más bien reformistas o directamente conservadores.

Generalmente, los trabajos sobre liderazgo político se ubican en una de tres posturas: 1) se concentran en la figura del líder y sus rasgos personales; 2) revisan el 
contexto social que permite el surgimiento del liderazgo; 3 ) intentan comprender y vincular ambos fenómenos, en una síntesis de posturas. Esta tercera postura conocida como «nuevo liderazgo» es teóricamente compleja, pues al intentar articular el agente y la estructura, se topa con varios de los problemas micro/macro (o agente/ estructura) que han perseguido a los sociólogos teóricos desde hace tiempo. Quizá por esto, algunos han intentado articular estos elementos con sociología que mezcla sujeto y estructura, como lo hace Bourdieu (Collado, Jiménez y Entrena, 2016).

Los estudios sobre liderazgo también suelen encaminarse a analizar cómo personas particulares han jugado roles relevantes en los partidos políticos (Mirón y Espinoza, 2004). Lo que se vincula mucho con este trabajo, pues se ha encontrado que los jóvenes parecen más susceptibles a seguir a políticos particulares que a partidos (Cuna, 2006). Esto además nos trae de vuelta al tema de si la gente observa personas o instituciones. Como se dijo antes, los mexicanos parecen votar menos cuando no están satisfechos con la política, pero su acento parece estar en las personas más que en las instituciones (Gutiérrez, 2017). Así pues, el análisis de los liderazgos nos puede llevar a muchos lugares, pero aquí sólo se desea conocer si la evaluación de las personas en particular -candidatos- se relaciona con la intención del voto, por lo que el estudio se concentrará en ese elemento en específico. Más adelante se profundizará sobre cómo medir y descomponer la evaluación de candidatos.

De este modo, la mala evaluación de los candidatos podría reducir la intención de votar. Aunque también se ha sugerido que el partidismo determina tanto la evaluación como la participación. Además, es posible que una ética de votar por deber cívico «aunque los candidatos no convenzan», haga irrelevante todo este asunto. Sólo los datos empíricos nos podrán probar o refutar la hipótesis de este estudio.

Evidentemente, es preferible contar con variables de control relacionadas a otros aspectos del liderazgo político, asimismo incluir otras variables como el grado de sofisticación política. Sin embargo, como se verá más adelante, no hubo forma viable de usar encuestas ya levantadas que incluyeran ese tipo de variables. Esto implicó el levantamiento de una encuesta propia, lo que limitó fuertemente la cantidad de reactivos que fue posible agregar, esto a su vez dejó fuera muchos elementos que habrían sido interesantes sobre el tema de los liderazgos. El control que se conservó lo mejor posible fue la adhesión partidista, pues esta variable representa el polo opuesto de una evaluación basada en candidatos y resulta obligatoria ante la posibilidad de que el partidismo determine también el juicio ciudadano de los políticos.

\section{Metodología}

Medir la intención de voto no es muy complejo, contrario a medir el juicio ciudadano sobre los candidatos. Lo recién explicado nos hace pensar que la evaluación que los 
ciudadanos hacen de los candidatos podría influir en la participación, pero no nos da mucha certeza sobre cómo las personas evalúan y juzgan a los políticos. El estudio de Gutiérrez (2017) sugiere una dimensión moral de la evaluación ciudadana. Pero los enfoques politológicos más racionales sugerirían una evaluación pragmática basada en cualidades vinculadas con la capacidad de manejo de funciones públicas.

Para indagar un poco más al respecto, el trabajo comenzó con una fase cualitativa. Se realizaron 9 entrevistas semi-estructuradas que indagaban cómo la gente veía y juzgaba a los candidatos. Coincidiendo con lo antes descrito, los informantes no parecen interesarse en los partidos o instituciones, sino en personas y dicen poner atención tanto a un elemento pragmático relacionado con cuán competentes parecen los candidatos (formación académica, propuestas, experiencia laboral), como a uno moral (si los candidatos son buenas personas). Esta información se utilizó para generar reactivos de un cuestionario que se mostrarán más adelante.

Los entrevistados más pesimistas en relación con lo moral eran los que menos seguros estaban de que sí votarían, pero claramente 9 entrevistas no serían suficientes. Originalmente, se planeó utilizar las entrevistas para seleccionar reactivos de grandes encuestas nacionales y generar uno o varios índices. Lamentablemente, las entrevistas apuntaron a un tipo de evaluación ciudadana (sobre todo moral) que no coincidió con ninguna pregunta en las encuestas nacionales, lo que -desafortunadamente- implicó que se tenía que levantar una nueva encuesta propia.

Se habría preferido -con mucho- utilizar alguna de las encuestas comunes en ciencia política, pues cuentan con una muestra grande y con representatividad nacional. Además, tienen una cantidad de variables muy grande, lo que habría permitido incluir controles sobre ingreso, interés e involucramiento en la política, apoyo a la democracia, participación no formal, entre otros. Pero fue imposible encontrar en esas bases algún reactivo sobre si los gobernantes o candidatos eran «buenas personas». Por ello, se generó un nuevo instrumento basado en las entrevistas. Esto resta representatividad estadística a lo aquí encontrado, pero a cambio, aporta precisión a los hallazgos, pues fue posible hacer que cada pregunta replicara con precisión las respuestas de los entrevistados.

Para medir la participación, el instrumento elaborado incluyó las afirmaciones: «Estoy seguro de que votaré en esta elección presidencial» $\mathrm{y}$ «Tengo credencial de elector vigente y el día de la elección estaré en la ciudad donde estoy registrado.» ambas con 4 posibles opciones de respuesta; acuerdo total, poco acuerdo, poco desacuerdo y desacuerdo total. Asimismo, se preguntó: «¿Cómo evalúas a los principales candidatos a la presidencia...?»; «Con relación a su formación académica y experiencia profesional»; «Con relación a sus valores y calidad moral»; «Con relación a sus 
propuestas y equipo de trabajo», estas últimas con 3 posibles respuestas: «Todos son malos», «hay buenos y malos» $\mathrm{y}$ «todos son adecuados».

Estas 3 variables no son casuales, pues como ya se dijo, las 3 aparecieron frecuentemente en las entrevistas como aspectos a los que la gente ponía atención de los candidatos. Además, la primera y la última hablan de una evaluación más bien pragmática cercana a las teorías racionales de la acción política y la segunda recupera el elemento moral al que algunos estudios sugieren.

Dado que se trataba de un cuestionario levantado para este estudio y no se contaban con demasiados recursos, no se pudieron agregar demasiadas variables de control, por lo que sólo se incluyeron dos: «Me identifico con algún partido político» $\mathrm{y}$ «Votar es mi deber ciudadano aun si los candidatos no me convencen del todo», ambas variables responden a posturas teóricas ya mencionadas.

Como ya se aclaró, este trabajo analiza estudiantes de licenciatura. Dicha población no sólo forma parte de la importante juventud nacional, sino que también tiene la ventaja de que es accesible y al ser fácil de encuestar, se pueden conseguir muestras razonables con recursos escasos. Además, se sabe que no es políticamente muy atípica (Gutiérrez, 2017). Para la encuesta se evitaron las facultades de estudios políticos y sociales, así como escuelas privadas.

Intentando tener una muestra federal, se encuestó en las ciudades de México, Guadalajara, Monterrey, Puebla, Querétaro y Villahermosa, con 100 estudiantes por ciudad. Las primeras 4 son las mayores urbes de la república, de hecho, juntas incluyen casi un tercio de toda la población de México, así pues, tanto por su tamaño, como por su representatividad de las grandes urbes, estas ciudades fueron indispensables. Querétaro es la décima zona metropolitana más habitada y se ubica en la zona centro del país, esta ciudad fue elegida por representar a una localidad media, está ubicada en el centro de la nación, sin ser propiamente del valle de México, lo que la hace un buen representante de la región centro del país, con ella se tiene un ejemplo de ciudad «mediana». Finalmente, Villahermosa es la ciudad número 22 por orden de población y se le eligió principalmente por ser una ciudad pequeña y del sureste (contrario a todas las demás). La encuesta fue levantada entre el 23 de abril y el 24 de mayo 2018. En total, se consiguió una muestra de 690 casos, con $45.4 \%$ de varones, $53.3 \%$ de mujeres, una edad promedio de 21.1 años y desviación estándar de 2.9

\section{4.- Resultados}

La exposición de los resultados comienza con una parte meramente descriptiva, luego se pasa al cruce de variables haciendo análisis de sólo dos variables por vez y finalmente, se hacen modelos de regresión múltiple con la intención de conocer si las relaciones encontradas en los cruces son espurias. Comenzando con los resultados, se preguntó si la persona estaba segura de que votaría en la elección 2018, sólo el 5.9\% 
dijo estar en desacuerdo total con esa idea, 4.5\% mostró poco desacuerdo, 15.7\% poco acuerdo y $73.6 \%$ acuerdo total (la participación oficialmente reportada en esta elección fue cercana al 60\%).

También, se preguntó al encuestado si contaba con credencial de elector y si estaría el 1 de julio en la ciudad en que está registrado, el 93\% manifestó algún grado de acuerdo con esta idea, pero 32 casos (4.6\%) dijeron estar en desacuerdo total, dado que estos casos no podrían votar aunque lo quisieran, fueron excluidos de todos los análisis de regresión.

Durante los análisis estadísticos, se evitó el uso de variables ordinales, pues éstas implican la creación de variables dummy o el uso de regresiones logísticas polinómicas u ordenadas, ambos procedimientos demandan un tamaño de muestra mayor al que se tenía y complican la interpretación de los resultados. En pos de la simplicidad, las variables fueron reducidas a dicotomías, la variable dependiente de participación se redujo a valores 1 (sí vota) para aquellos que dijeron «acuerdo total» en ambas preguntas antes mencionadas y 0 (no vota) para cualquier otra combinación de respuestas (exceptuando los 32 casos que dicen no poder votar y que quedaron como datos perdidos). Esto generó una variable con un $74.9 \%$ de participación estimada, misma que no mostró relación estadísticamente significativa con la ciudad de donde proviene el caso, aunque sí hubo algunas diferencias al respecto:

Gráfico 1

Participación electoral estimada por ciudad.

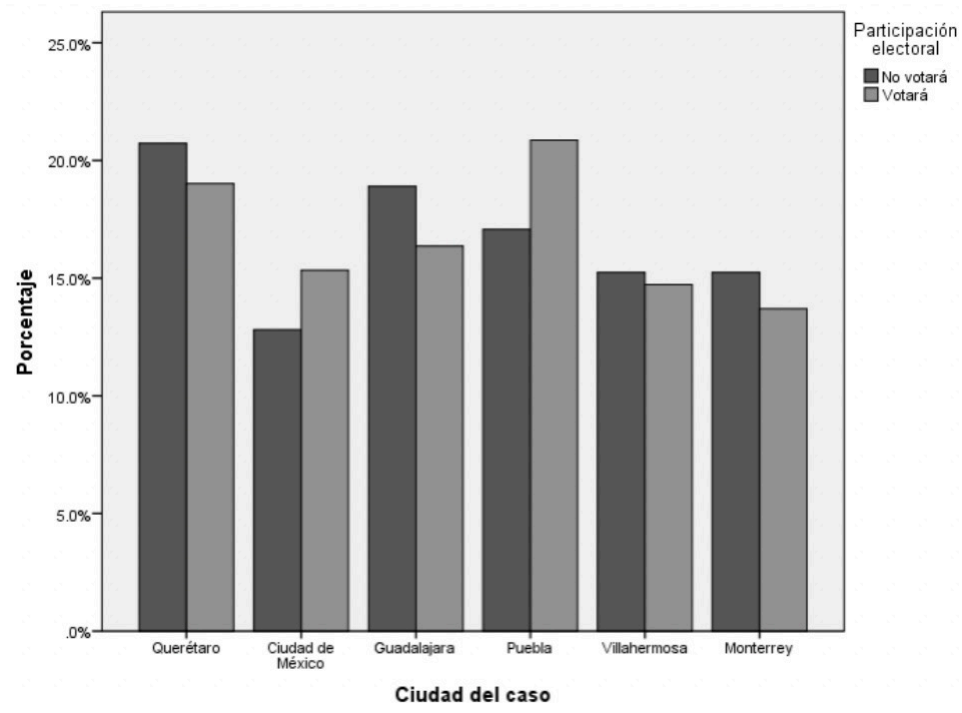

Fuente: Elaboración propia con datos propios. 
En Guadalajara, Nuevo León y Querétaro parece haber una preferencia por no votar, Puebla y la Ciudad de México muestran la tendencia inversa, mientras en Villahermosa no hay tendencia clara. Este resultado pareciera repetir la ambigüedad de la teoría de la modernización, pues la Ciudad de México (la capital y una de las ciudades más desarrolladas del país) muestra una alta participación, mientras que la segunda y tercera mayor urbe (ambas económicamente prósperas) dijeron ser las que menos votan, luego vendría Puebla, capital de un estado con abundante pobreza y que parece votar mucho.

Sobre la opinión acerca de los candidatos, se encontró que el grueso de los informantes percibía que había buenos y malos candidatos, mientras que lo moral fue lo peor evaluado:

\section{Gráfico 2}

Opinión de los principales candidatos a la presidencia

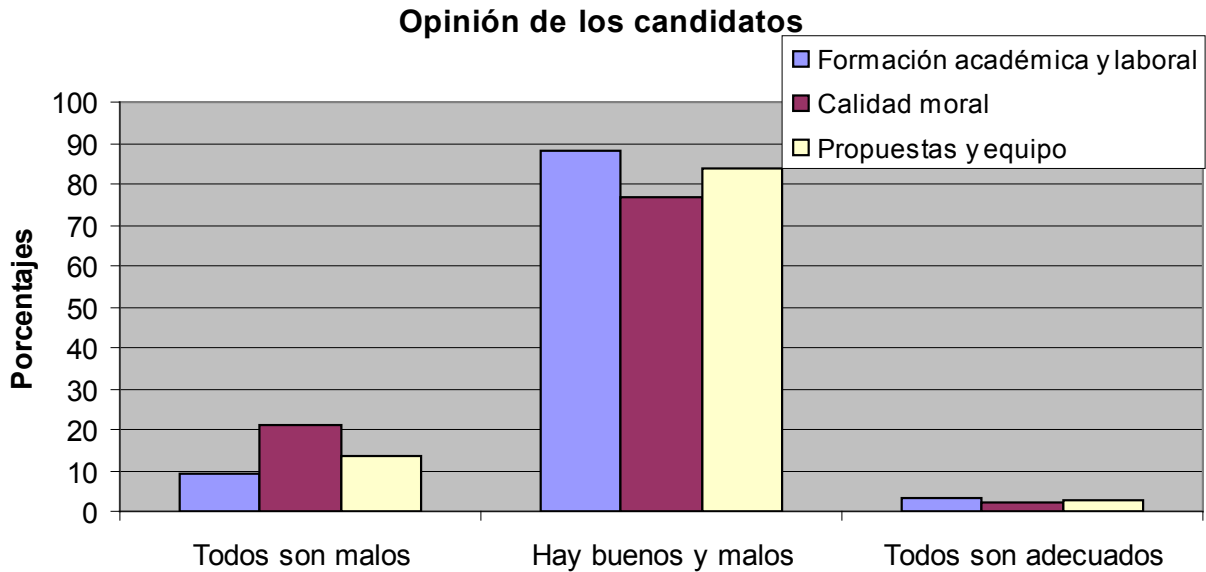

Fuente: Elaboración propia con datos propios.

Muy pocas personas (alrededor de 3\%) creían que todos los candidatos eran buenos, por lo que se colapsaron categorías y se conservó sólo una variable dicotómica por aspecto, misma que era 1 cuando la persona pensaba que todos los candidatos eran malos y 0 cuando no.

Se revisaron también dos variables de control, el apego partidista y el deber de votar aun si los candidatos son malos. Para medir el partidismo se preguntó: «Me identifico con algún partido político» en el que el $62.2 \%$ de los encuestados manifestaron algún grado de acuerdo contra el 37.8\% que mencionó no hacerlo. Esto 
refuerza la idea de que muchas personas ya no tienen un apego partidista. Por otro lado, se incluyó el reactivo: "Votar es mi deber ciudadano aun si los candidatos no me convencen del todo», el 63.7\% de los informantes dijo estar en completo acuerdo con esta idea, por lo que ese porcentaje se transformó en valor «1» de una variable dicotómica.

Hecho ya el análisis descriptivo, se pasa ahora al cruce de variables. Como se mencionó desde la introducción, el principal objetivo de este trabajo es conocer si una mala evaluación sobre los candidatos implica una menor intención de voto. Para investigar esto, se tomaron las variables antes descritas y se hicieron cruces entre la evaluación de los candidatos (en sus 3 variables/rasgos) y la intención de votar. Estas primeras pruebas estadísticas fueron de $\mathrm{X}^{2}$ para tabla de contingencia y con ellas se encontró que quienes valoran a todos los candidatos como malos tienden a votar menos, ya sea que se tome el tema moral, el académico/profesional o el de propuestas/equipo, en todos los casos, los valores $\mathrm{P}$ resultan menores a .001:

Tabla 1

Relaciones entre evaluaciones de candidatos e intención de voto

\begin{tabular}{|c|c|c|c|c|}
\hline \multicolumn{2}{|c|}{ Evaluaciones de los candidatos } & \multicolumn{3}{|c|}{ Intención de voto } \\
\hline & & Votará & No votará & Total \\
\hline \multirow{3}{*}{$\begin{array}{l}\text { Sobre su formación } \\
\text { académica y laboral }\end{array}$} & Todos son malos & $28(45.9 \%)$ & $33(54 \%)$ & $61(100 \%)$ \\
\hline & No todos son malos & $460(74 \%)$ & $161(25.9 \%)$ & $621(100 \%)$ \\
\hline & \multicolumn{4}{|l|}{ Valor $X^{2}=21.6 P=.000003$} \\
\hline \multirow{3}{*}{ Sobre su calidad moral } & Todos son malos & $85(58.6 \%)$ & $60(41.3 \%)$ & $145(100 \%)$ \\
\hline & No todos son malos & 402 (75.1\%) & $133(24.8 \%)$ & $535(100 \%)$ \\
\hline & \multicolumn{4}{|l|}{ Valor $X^{2}=15.31 P=.00009$} \\
\hline \multirow{3}{*}{$\begin{array}{l}\text { Sobre sus propuestas } \\
\text { y equipo }\end{array}$} & Todos son malos & $52(55.3 \%)$ & $42(44.6 \%)$ & $94(100 \%)$ \\
\hline & No todos son malos & $435(74.2 \%)$ & $151(25.7 \%)$ & $586(100 \%)$ \\
\hline & \multicolumn{4}{|l|}{ Valor $\mathrm{X}^{2}=14.2 \mathrm{P}=.00016$} \\
\hline
\end{tabular}

Fuente: Elaboración propia con datos propios.

La tabla de arriba deja claro que sí hay una relación entre cómo los jóvenes evalúan a los candidatos y su intención de votar o no hacerlo. Es decir, quienes piensan 
que los candidatos son malos, tienen menos propensión a votar, ya sea que se revise la formación académica/laboral de los contendientes, su aspecto moral o sus equipos y propuestas.

No obstante, este no puede ser el final de los análisis. La parte teórica no sólo mostraba cómo esta relación distaba de ser obvia, sino que también presentó dos ideas que obligaron a tener preguntas de control. La primera sugiere que en realidad es el partidismo el que determina la participación electoral (quienes se identifican con algún partido son quienes votan más) y que, de hecho, el partido llega incluso a determinar cómo la gente evalúa a los candidatos y gobiernos. Esto es particularmente importante porque quizá significa que los cruces de variables de la tabla anterior sólo contienen relaciones estadísticamente espurias que serán controladas por el partidismo.

Por otro lado, se mencionó un estudio que sugería la presencia de una ideología según la cual las personas votaban porque era su deber cívico independientemente de si los candidatos les convencían o no, lo que -de ser correcto- podría implicar que la evaluación de los candidatos ulteriormente no es relevante. Tanto la pregunta de control sobre identificación partidista como la idea de votar aunque los candidatos no convenzan mostraron tener una relación estadísticamente significativa con la intención del voto:

Tabla 2

Relaciones entre variables de control e intención de voto

\begin{tabular}{l|c|c|c}
\hline \multirow{2}{*}{} & \multicolumn{3}{|c}{ Intención de voto } \\
\cline { 2 - 4 } & Votará & No votará & Total \\
\hline Se identifica con algún partido & $219(85.2 \%)$ & $38(14.7 \%)$ & $257(100 \%)$ \\
\hline No se identifica con algún partido & $269(63.4 \%)$ & $155(36.5 \%)$ & $424(100 \%)$ \\
\hline Valor $X^{2}=52.7$ P<.00001 & & & \\
\hline Se debe votar aunque los candidatos no convenzan & $352(81.1 \%)$ & $82(18.8 \%)$ & $434(100 \%)$ \\
\hline No se debe votar si los candidatos no convencen & $134(54.9 \%)$ & $110(45 \%)$ & $244(100 \%)$ \\
\hline Valor $X^{2}=37.3 P<.00001$ & & & \\
\hline \hline
\end{tabular}

Fuente: Elaboración propia con datos propios.

Así, la evaluación relativa a candidatos (en todas sus facetas) se relaciona con la intención del voto; del mismo modo, la identificación partidista y la idea de que votar 
no debería depender del convencimiento también se vinculan con si el informante votará o no.

Antes de pasar a las regresiones con controles de variables, vale la pena señalar que no sólo se encontró relación estadística en cruces de variables que incluían la variable dependiente de intención de voto, sino que -inexplicablemente- las facetas de la evaluación sobre los candidatos también se relacionaron entre sí. Es decir, quienes tendían a creer que todos los candidatos eran malos en cuanto a lo moral, también tendían a creer que lo eran en cuanto a su formación académica y laboral, así como en relación con sus propuestas y equipo de trabajo. Además, quienes creían que los candidatos eran malos en lo académico/profesional, también pensaban que no eran buenas las propuestas ni equipos de trabajo

Tanto los resultados de las variables de control, como la relación entre aspectos de la evaluación de candidatos nos invitan a utilizar modelos de regresión. La regresión es relevante para las variables de control porque mostrará si la evaluación de candidatos efectivamente es relevante o sólo es un reflejo secundario del apego partidista o de la idea de votar aunque no convenzan los candidatos. Por otro lado, la misma regresión nos dirá si de verdad todos los aspectos de la evaluación de candidatos son relevantes o si algunos sólo son el reflejo de otros aspectos que son los que realmente tienen peso en la intención de voto.

Dado que la regresión en cuestión tiene como variable dependiente la intención de votar, se usó un modelo logístico dicotómico. Cuando se incluyen las 3 variables de evaluación sobre candidatos se obtiene un modelo donde el factor moral tiene un $\mathrm{P}$ de .003, el profesional/académico de $.002 \mathrm{y}$ el de propuestas/equipo .135, lo que deja claro que esta última evaluación ciudadana en realidad no tiene relación con la intención del voto y que sólo se relaciona con alguna de las otras evaluaciones que sí impactan la participación, esto a su vez hace eco de aquella idea según la cual la ciudadanía fija su atención en las personas -candidatos en este caso-, dejando de lado el equipo o las propuestas.

El modelo de regresión con las 3 evaluaciones de candidatos y las 2 variables de control confirma que las propuestas y el equipo de trabajo no importan al arrojar un valor P de .446 en esa variable. Sin embargo, en este modelo la evaluación de la formación profesional también deja de ser significativa con un valor P de .089, mientras que el juicio moral, la identificación partidista y el deber del voto se muestran claramente significativas con valores $P$ menores a .01. Vale la pena señalar que, si se quita la variable de las propuestas/equipo y se conserva sólo la moral, las de control y la profesional/académica, esta última aparece como -apenas- significativa, con un $\mathrm{P}$ de .044, en dicha regresión, el juicio moral presenta un valor P de .003, haciéndonos pensar que lo moral parece determinar más el abstencionismo que la preparación del candidato: 
Tabla 3

Regresión logística final

\begin{tabular}{|c|c|c|c|c|}
\hline \multicolumn{5}{|c|}{ Regresión logística con sólo variables de $\mathrm{P}<.05$} \\
\hline Variable independiente: & B & E.T & $\mathbf{P}$ & OR \\
\hline Opinión moral de candidatos & -.682 & .231 & .003 & .505 \\
\hline Opinión sobre lo académico/ laboral de candidatos & -.640 & .318 & .044 & .527 \\
\hline Apego partidista & .240 & .240 & .000 & 3.303 \\
\hline Debe votar aun si candidatos no convencen & .204 & .204 & .000 & 3.525 \\
\hline
\end{tabular}

Fuente: Elaboración propia con datos propios.

En este último modelo, las variables de control tienen mayor peso estadístico que las de juicio a candidatos. Tener apego partidista o creer que se debe votar pese a los malos candidatos triplica los momios de votar (OR 3.3 y 3.5), mientras que creer que todos los candidatos son malos moralmente o en el sentido profesional/académico sólo reduce los momios del voto a la mitad (OR .505 y .527).

Con estos datos, podemos decir que el voto sí está determinado por el partidismo, pero contrario a lo dicho por defensores del modelo Michigan, la identificación con algún partido no controla todo lo demás ni es un factor hegemónico. Además, sí hay cierta ideología que previene que la mala evaluación referente a los candidatos afecte la participación, pero eso no elimina el rol de la evaluación sobre los políticos. Así, el juicio ciudadano afecta la participación; cuando la gente cree que todos los candidatos son malos, votan menos, lo que parece suceder más con la opinión moral que con la profesional/académica.

Antes de pasar a las conclusiones, vale la pena señalar que los modelos de regresión cambiaban cuando sólo se consideraba una parte de la muestra. Si sólo se incluían los casos de Guadalajara y Monterrey (ciudades del nor-occidente), el elemento moral dejaba de ser significativo y sólo lo era el profesional/académico, mientras que sólo si se consideraba el resto de la muestra pasó lo exacto opuesto. Esto podría ser una mera coincidencia debida al pequeño tamaño de muestra, o podría sugerir que el efecto de la evaluación moral/pragmática cambia según la región o alguna otra variable subyacente. 


\section{5.- Conclusiones}

La mala evaluación sobre los candidatos -moral principalmente- sí se vincula con que las personas voten o no, esto aun controlando a un partidismo que todavía explica pero parece ir en declive y a pesar de cierta ética que sugiere votar "por el menos malo» aunque los candidatos no convenzan. Esto debería ser un llamado de atención para actores e instituciones políticas nacionales, quienes por el bien de la democracia mexicana deben esforzarse por mejorar la oferta política.

No obstante, buscar que la oferta política sea más atractiva no sólo significa un esfuerzo porque los políticos sean «mejores», pues queda claro que el juicio ciudadano es complejo. Mejorar la imagen de los políticos y del gobierno tendría que empezar por una comprensión más profunda de cómo las personas juzgan y evalúan. Los ciudadanos no son simples observadores de variables objetivas como el crecimiento del PIB o el índice de homicidios, ponen atención a temas más complejos como la moral de los gobernantes y francamente sabemos poco sobre cómo se hace un juicio moral de alguien con quien no se tiene contacto directo y que sólo se percibe a través de medios de comunicación.

La democracia mexicana necesita que la ciudadanía vea mejor a sus candidatos y funcionarios en general, la participación electoral está en juego. Pero lograrlo dependerá de que se entienda más el juicio ciudadano, que armados con ese entendimiento se hagan cambios en puntos estratégicos y que -además- sean divulgados de la manera correcta. Esto es mucho más que sólo pedir que los políticos sean mejores.

En lo académico, este trabajo es sugerente no sólo por afirmar con evidencia empírica que la mala evaluación de los políticos sí se relaciona con el abstencionismo, sino -y principalmente- por encontrar que esta relación parece pasar más por la fase moral de los candidatos que por elementos pragmáticos. A su vez, estos hallazgos invitan a investigar más, es decir, se necesitan incorporar este tipo de elementos morales a encuestas y muestras de mucho mayor tamaño, en especial si se quiere analizar la posibilidad de que regiones particulares tengan juicios ciudadanos diversos.

También se debe recordar que la encuesta aquí presentada sólo incluyó estudiantes de licenciatura. Es posible que el elemento moral tenga aun más potencia explicativa que la aquí estimada cuando se considere población de menor educación y mayor edad. Pero sólo una encuesta grande y de representatividad nacional podrá decirlo.

El trabajo también sugiere una promisoria línea de investigación que necesita ser explotada. Los análisis matemáticos muestran que la mayoría de las personas suelen sincronizar sus evaluaciones en todas las áreas; profesional, académica, moral, propuestas y equipo, pero no hay una razón lógica apriorística por la que esto sea así y 
menos aún en el contexto mexicano de la elección 2018 con candidatos muy dispares es diferentes áreas.

No hay explicación a por qué las personas evalúan sincronizadamente todos los aspectos. Existe la posibilidad ya antes sugerida (Gutiérrez, 2018) de que las personas evalúan moralmente y a posteriori justifican su juicio con datos sobre economía, seguridad o historial de los candidatos, lo que también coincidiría con ciertas teorías sobre las emociones que -según parece- son racionalizadas a posteriori (Haidt, 2003; Lodge y Taber, 2005), pero nada de esto ha sido probado y demostrarlo parece difícil, pues se trata de una hipótesis según la cual el discurso del informante (razonado a posteriori) no coincidiría con sus determinantes verdaderas, generando discrepancias entre hechos y discursos.

Para hacer esto más complejo, es poco claro cómo es que las personas evalúan la moral y los valores de un candidato cuando no tienen contacto directo con él y sólo lo conocen a través de los medios de comunicación. Parece que comprender el juicio moral/racional del votante será arduo, pero es muy promisorio, pues los electores claramente no son los agentes racionales que la teoría económica sugeriría, ni tampoco votantes cognitivamente encausados por un apego partidista. Un modelo teórico que incorpore el juicio moral y el pragmático podría ser una importante herramienta para explicar la conducta electoral, lo que a su vez podría ayudar a generar mejores estrategias de comunicación social y políticas en general, coadyuvando a formar una ciudadanía más participativa y una democracia más sólida.

\section{6.- Bibliografía.}

ALONSO, Jorge (1994). «Partidos y cultura política», en Jorge ALONSO, (ed.). Cultura política y educación cívica, México: CIIH-UNAM, 115-184.

ALONSO, Jorge (2010). «El movimiento anulista en 2009 y la abstención», Espiral, 16 (47): 9-46.

CÁLIX, Álvaro y Willibald, SONNLEITNER (2006). «La paradoja hondureña: ¿Por qué los marginados votan tanto en Honduras?», en Willibald, SONNLEITNER (ed.). Explorando los territorios del voto: hacia un atlas electoral de Centroamérica, Guatemala: Centro de Estudios Mexicanos y Centroamericanos-Instituto de Altos Estudios de América Latina-Banco Interamericano de Desarrollo.

COLLADO, Francisco; José Francisco, JIMÉNEZ y Francisco, ENTRENARA (2016). «El liderazgo político en las democracias representativas: propuesta de análisis desde el constructivismo estructuralista», Revista Mexicana de Ciencias Políticas y Sociales, 61 (228): 57-90. https://doi.org/10.1016/s0185-1918(16)30040-x 
CUNA, Enrique (2006). «Reflexiones sobre el desencanto democrático. El caso de los partidos políticos y los jóvenes en la ciudad de México», Sociológica, 21 (61): 95-133.

CUNA, Enrique (2012). «Apoyo a la democracia en jóvenes estudiantes de la ciudad de México. Estudio sobre el desencanto ciudadano juvenil con las instituciones de la democracia mexicana», Polis: Investigación y Análisis Sociopolítico y Psicosocial, 8 (2): 107-151.

DALTON, Russell J. (1984). Cognitive mobilization and partisan Dealignment in advances industrial democracies, New Haven: Yale University Press.

DURAND, Manuel (1998). La cultura política de los alumnos de la UNAM, México: UNAM.

GUTIÉRREZ, Héctor (2017). «Buenos ciudadanos que no votan. Mecanismos entre desencanto y abstención», Sociológica, 32 (92): 141-173.

GUTIÉRREZ, Héctor (2018). «La desaprobación del gobierno mexicano. Más que ineficiencia», Espiral, 25 (72): 83-121. https://doi.org/10.32870/espiral. v25i72.6384

GUTIÉRREZ, Héctor y Marcela, ÁVILA (2019). «Partidos o candidatos-coyunturas; patrones espaciotemporales del voto mexicano 1994-2015», Tla-melaua, 13(46): 76-96. http://dx.doi.org/10.32399/rtla.0.46.195

HAIDT, Jonathan (2003). "The Moral Emotions», en Richard, DAVIDSON; KLAUS S. Sherrer y Harold, H. Goldsmith (eds.). Handbook of Affective Sciences, Oxford: Oxford University Press.

HOLZNER, Claudio A (2007). «Voz y voto: participación política y calidad de la democracia en México», América latina Hoy, 45: 69-87.

KROTZ, Esteban (1990). «Antropología, elecciones y cultura política», Nueva antropología, 11 (38): 9-19.

LAZARSFELD, Paul F. y Robert K. MERTON (1948). «Mass Communication, Popular Taste, and Organized Social Action», en Bryson LYMAN (ed.). The Communication of Ideas, New York: Harper.

LAZARSFELD, Paul F. (1969). The people's choice: how the voter makes up his mind in a presidential campaign, New York: Columbia University press.

LEHOUCQ, Fabrice y David L. WALL (2001). "¿La explicación es institucional o sociológica? Tasas de participación electoral en democracias nuevas», en Edelberto TORRES et al (ed.). Construyendo la democracia electoral en Guatemala, Guatemala: Facultad Latinoamericana de Ciencias Sociales.

LEHR G. Volker (1985). «Modernización y movilización electoral 1964-1976. Un estudio ecológico», Estudios políticos, 4 (1): 115-154. 
LIZAMA, Guillermo (2012). «Geografía electoral del abstencionismo en los municipios de México (1994-2009)», Especialidades, 2 (2): 23-51.

LODGE, Milton y Charles, TABER (2005). «The Automaticity of Affect for Political Leaders, Groups, and Issues: An Experimental Test of the Hot Cognition Hypothesis», Political Psychology, 26 (2): 455-482.

LÓPEZ, Rogelio (2013). «El abstencionismo como fenómeno político en la sociedad contemporánea». Culturales. 1 (1): 53-68.

LUTZ, Bruno (2005). «La participación electoral inconclusa: abstencionismo y votación nula en México», Revista Mexicana de Sociología, 67 (4): 793-826.

LUTZ, Bruno (2005a). «El palimpsesto del abstencionismo electoral en México o la democracia a prueba», Espacios públicos, 8, (15): 51-76

MIRÓN Rosa María y Ricardo, ESPINOZA (coord.) (2004). Partidos políticos. Nuevos liderazgos y relaciones internas de autoridad. México: Universidad Autónoma Metropolitana, Asociación Mexicana de Estudios Parlamentarios e Instituto de Investigaciones Jurídicas de la universidad Nacional Autónoma de México.

MOLINAR, Juan y Rafael, VERGARA (1998). «Los estudios sobre el elector mexicano. Cuatro enfoques de análisis electoral en México», Fernando MIGALLÓN (coord.). Homenaje a Rafael Segovia, México: El Colegio de México.

MORENO, Alejandro (2009). La decisión electoral. Votantes, partidos y democracia en México, México: Porrúa.

MORENO, Alejandro y Patricia MÉNDEZ (2007). «La identificación partidista en las elecciones presidenciales de 2000 y 2006 en México», Política y gobierno, 14, (1): 43-75.

MORA, Juan y Raúl, RODRÍGUEZ (2003). «Las elecciones intermedias del 2003: entre el desencanto político y la crisis de representación», El Cotidiano, 19 (122): 55-65.

MORALES, Martha; Henio, MILLÁN; Marcela, ÁVILA y Luis Alberto, FERNÁNDEZ (2011). Participación y abstencionismo electoral en México, México: Instituto Federal Electoral.

REYNA, José Luis (1971). An empirical analysis of political mobilization: the case of Mexico, Ithaca: Cornell University.

RIKER, William H. y Peter C. ORDESHOOK (1968). «A theory of the calculus of voting». The American Political Science Review, 62 (1): 787-792.

SALAZAR, Pedro (2002). «Participación política y ciudadana de los jóvenes», en José Antonio PÉREZ (ed.). Jóvenes: una evaluación de su conocimiento, México: Instituto Mexicano de la Juventud-Secretaría de Educación Pública, 529-603. 
SONNLEITNER, Willibald (2007). «Participación electoral y desarrollo humano: apuntes metodológicos para el análisis territorial y multidimencional del voto en México y Centroamérica», Estudios Sociológicos, 25 (75): 813-835.

URBINA, Gustavo Adolfo (2014). De jóvenes a adultos y de estudiantes a ciudadanos: Un estudio sobre la relación entre el proceso de activación cívica y la transición a la vida adulta en jóvenes universitarios de la ciudad de México. Tesis para obtener el grado de Doctor en Ciencia Social, México: El Colegio de México.

VILALTA, Carlos (2004). "The local context and the spatial diffusion of multiparty competition in Urban Mexico», Political Geography, (23): 403-423.

ZOVATTO, Daniel (2006). «La participación electoral en América Latina: tendencias y perspectivas», Tribunal Electoral del Poder Judicial de la Federación, Cultura democrática: abstencionismo y participación. Memoria del IV Congreso internacional de derecho electoral, México: Tribunal Electoral del Poder Judicial de la Federación. 
